\title{
Effects of Literacy and Education on Semantic Fluency in the Korean Elderly
}

\author{
Jinkyung Lee ${ }^{\mathrm{a}}$, Yeonwook Kang, \\ ${ }^{a}$ Department of Psychology, Hallym University, Chuncheon, Korea \\ ${ }^{b}$ Department of Neurology, Hallym University Sacred Heart Hospital, Anyang, Korea
}

\author{
Correspondence: Yeonwook Kang, PhD \\ Department of Psychology, Hallym University, \\ 1 Hallymdaehak-gil, Chuncheon 24252, Korea \\ Tel: $+82-33-248-1724$ \\ Fax: +82-33-256-3424 \\ E-mail: ykang@hallym.ac.kr
}

Received: October 5, 2016

Revised: November 17, 2016

Accepted: November 29, 2016

This work was supported by Hallym University Research Fund (HRF-201609-002) and the National Research Foundation of Korea (NRF2014S1A5A2A03065709).

\begin{abstract}
Objectives: The present study was conducted to examine the effects of literacy and education on semantic fluency and to compare them to two semantic categories such as animal and supermarket. Methods: Normal healthy elderly $(\mathrm{N}=306$; mean age: $72.8 \pm 7.8$ years; 151 male, 155 female) participated in the study. The participants were classified into 7 groups: illiterate group $(\mathrm{N}=30)$, no schooling but literate group $(\mathrm{N}=40)$, lower grade of elementary school group $(\mathrm{N}=24)$, higher grade of elementary school group $(\mathrm{N}=55)$, middle school group ( $N=52)$, high school group ( $N=51)$, and college group $(N=54)$. All of the participants were given the semantic (animal \& supermarket) fluency test. Results: There was a significant group difference between the illiterate and no schooling but literate groups in the animal category, whereas no significant group difference was found between the illiterate and lower grade of elementary school groups in the supermarket category. In the animal category, there was no significant group difference between the no schooling but literate and middle school groups or between the high school and college groups, whereas the performance was better on the supermarket category test in the higher grade of elementary school than the illiterate groups, and in the middle school than no schooling but literate groups, and in the college than high school groups. Conclusion: The results suggest that literacy has a stronger influence on animal fluency while education has a stronger influence on supermarket fluency.
\end{abstract}

Keywords: Literacy, Education, Semantic fluency, Animal category, Supermarket category
구어 유창성(verbal fluency)이란 기존에 저장되어 있는 어휘집 (lexicon)과 의미기억(semantic memory)으로부터 정보를 전략적 으로 탐색하고 인출하는 능력을 말한다(Sauzéon, Lestage, Raboutet, N'Kaoua, \& Claverie, 2004). 구어 유창성을 평가하기 위해서 임상장면에서는 주로 통제단어연상검사(Controlled Oral Word Association Test, COWAT; Lucas et al., 1998)를 사용하는데 COWAT은 실시하기가 쉽고 간편하면서도 뇌손상과 인지저하를 예민 하게 탐지해내는 것으로 알려져 있다(Acevedo et al., 2000).

COWAT은 음소 유창성검사와 의미 유창성검사로 구성되어 있 다. 음소 유창성검사는 특정 음소( ᄀ , O, ㅅ)로 시작하는 단어를, 의미 유창성검사는 특정 범주(동물, 가게물건, 채소, 과일, 교통수 단 등)에 해당하는 단어를 제한시간 1 분 동안 최대한 많이 이야기 하도록 하는 검사이다. 음소 유창성과 의미 유창성은 각각 서로 다
른 뇌 영역이 담당하는 것으로 알려져 있는데, 음소 유창성 능력은 어휘-음운기억(lexical-phonemic memory)을 담당하는 전두엽의 기능과 관련이 있고, 의미 유창성 능력은 전두엽 뿐만 아니라 의미 기억(semantic memory)을 담당하는 측두엽 영역과도 관련이 있는 것으로 알려져 있다(Baldo, Schwartz, Wilkins, \& Dronkers, 2006; Birn et al., 2010). 따라서 의미 유창성검사는 병의 초기부터 측두엽 의 손상을 보이는 알츠하이머병 환자들은 물론 전두엽 장애를 특 징적으로 나타내는 혈관성 인지장애 환자들이나 파킨슨병 환자들 에 이르기까지 다양한 환자 집단을 대상으로 사용되어 왔다(Abrahams et al., 2000; Hock et al., 1997; Kim, Kang, Yu, \& Lee, 2015; Mo, Sung, \& Jeong, 2015; Park et al., 2006; Troyer, Moscovitch, Winocur, Leach, \& Freedman, 1998).

또한, 의미 유창성검사는 글을 읽거나 쓰지 못하는 비문해자들 
에게도 실시가 가능하기 때문에 문해자에게만 실시할 수 있는 음 소 유창성검사와는 달리 학력의 제한없이 모든 사람들에게 생성이 름대기능력(generative naming ability)을 평가할 수 있다는 장점을 지닌다. 더욱이 65세 이상의 노인 중 무학이 $30.5 \%$ 를 차지하고 이 중 9.6\%가 글자를 전혀 모르는 비문해자인(Jung et al., 2014) 우리 나라의 경우, 치매여부를 평가하는 임상현장에서 구어 유창성을 평가하기 위해서는 비문해자에게도 검사실시가 가능한 의미 유창 성검사가 유일하게 사용될 수 있는 검사이다. 그러나 언어 유창성 과 관련하여 국내외에서 수행된 선행연구들을 살펴보면, 음소 유 창성의 경우, 교육년수와 나이의 영향을 많이 받는 반면에 성별의 영향에는 민감하지 않고(Choi, 2012b; Geiser \& Vanderploeg, 1993; Selnes et al., 1991; Yeudall, Fromm, Reddon, \& Stefanyk, 1986), 정 상 집단과 비교했을 때 알츠하이머형 치매와 혈관 치매 모두 초기 단계에서부터 두드러지게 저하된다는 등(Fahlander, Wahlin, Almkvist, \& Bäckman, 2002; Hart \& Best, 2014; Henry, MacLeod, Phillips, \& Crawford, 2004; Jones, Laukka, \& Bäckman, 2006; Pakhomov \& Hemmy, 2014; Park et al., 2006) 다양한 주제로 활발하게 연구가 수행되었으나 의미 유창성만을 다룬 연구들은 상대적으로 많지 않다(Bolla, Lindgren, Bonaccorsy, \& Bleecker, 1990; Capitani, Laiacona, \& Basso, 1998; Loonstra, Tarlow, \& Sellers, 2001; Phillips, 1999; Rodriguez-Aranda \& Martinussen, 2006). 특히, 의미 유 창성검사가 비문해자의 구어 유창성을 평가하는데 유용한 평가치 가 될 수 있는지, 즉 의미 유창성검사를 비문해자에게 실시할 수는 있지만 의미 유창성검사의 수행이 학력의 영향을 전혀 받지 않는지 에 관해서는 기존에 수행된 소수의 의미 유창성 연구들에서도 다 음과 같이 일관되지 않는 결과들을 보고하고 있다.

Sa, Chey와 Suk (2011)은 문맹-저교육, 문해-저교육 및 문해-고교 육 집단의 의미 유창성을 비교한 결과, 문해자가 비문해자보다 동 물과 가게물건 범주에서 더 많은 반응을 산출한다는 사실을 확인 하였지만 교육수준에 따른 집단 간 수행차이를 발견하지는 못하였 다. 그러나, 외국에서 수행된 연구에서는 비문해자/무학 집단이 문 해자/저학력 집단보다 의미 유창성검사에서 저조한 수행을 보였 고, 문해자/저학력 집단은 문해자/고학력 집단보다 유의하게 저조 한 수행을 보이는 것으로 보고되었다(Kosmidis, Tsapkini, Folia, Vlahou, \& Kiosseoglou, 2004). 동물 범주를 사용하여 고학력(senior vocational training or academic training) 집단과 저학력(primary education) 집단을 비교한 다른 연구에서도 고학력 집단이 저학력 집단보다 유의미하게 우수한 수행을 보이는 것으로 나타났 다(Van Der Elst, Van Boxtel, Van Breukelen, \& Jolles, 2006). 교육 수준을 더 세분하여 비교한 또 다른 연구에서는 비문해 집단이 교
육수준 1-4년 집단하고는 유의한 수행차이를 보이지 않았으나 교 육수준 8년 이상의 집단하고는 유의한 수행차이가 있음을 발견하 였다(Brucki \& Rocha, 2004). 선행연구들의 결과에서 관찰되는 이 런 차이는 우선, 연구마다 학력 집단을 분류하는 방법이 다르고 보 다 자세한 학력 분류에 따른 비교가 이루어지지 않았기 때문으로 생각된다. 즉, 대부분의 선행연구들은 집단을 단순히 비문해 집단 과 문해 집단으로 구분함으로써 문해 집단의 평균 교육년수가 연 구들마다 다르고(Da Silva, Petersson, Faisca, Ingvar, \& Reis, 2004; Kwon, Cho, Seo, \& Na, 2012; Youn et al., 2011), 문해 집단을 교육년 수에 따라서 더 세분화한 연구들도 2개(저학력과 고학력) 정도의 소수의 집단으로만 나누어 비교함으로써 교육수준이 의미 유창성 에 미치는 효과를 자세히 확인하지 못하였다(Ardila, Ostrosky-Solis, Rosselli, \& Gómez, 2000; Sa et al., 2011).

학력 집단을 분류하는 방법의 차이와 함께 의미 유창성검사에 서 사용된 의미범주의 차이도 선행연구 결과의 차이에 영향을 미 쳤을 것으로 생각된다. 의미 유창성검사에서 사용되는 범주로는 동물, 가게물건(슈퍼마켓에서 살 수 있는 물건), 과일, 채소, 음식, 옷, 가구 등이 있으나 가장 흔히 사용되는 범주는 “동물”과 “가게 물건”이다. 연구 대상을 문해 집단과 비문해 집단으로 분류하여 비 교한 연구들 중 동물 범주에서는 두 집단 간의 차이가 발견되었으 나, 가게물건 범주에서는 유의한 수행차이가 발견되지 않은 연구가 있었고(Da Silva et al., 2004; Kwon et al., 2012; Nielsen \& Walde$\operatorname{mar}, 2016)$ 그와는 반대로 동물 범주에 있어 문해 집단과 비문해 집 단 간의 수행차이가 유의하지 않다는 연구 결과도 있었다(Youn et al., 2011). 그러나 또 다른 연구에서는 동물과 가게물건 범주 모두에 서 문해 집단과 비문해 집단 간의 수행차이가 관찰되지 않았다 (Kwon, Yoon, \& Na, 2015). 최근 Nielsen과 Waldemar (2016)는 터 키에서 덴마크로 이주해 온 이민자들에게 동물과 가게물건 범주에 대한 의미 유창성검사를 실시하고 문식성의 여부가 의미 유창성에 미치는 영향력이 범주에 따라서 다르다는 사실을 보고하였다. 즉, 동물 범주에서는 비문해자와 문해자 집단 간의 유의한 수행차이가 관찰되었으나 가게물건 범주에서는 두 집단의 차이가 관찰되지 않 았다. 연구자들은 이러한 결과에 근거하여 임상현장에서 덴마크어 를 읽고 쓰지 못하는 비문해 터키 이민자들의 생성이름대기능력을 평가할 때에는 문식성의 영향을 받지 않는 가게물건 범주를 실시 하는 것이 타당하다고 주장하였다.

또한 의미범주에 따라서 성별이 의미 유창성검사의 수행에 미치 는 영향에 대해서도 연구자들은 서로 다른 결과를 보고하였는데, 국내외 연구들을 살펴보면, 전체 반응 수가 남성은 가게물건 범주 보다 동물 범주에서, 여성은 동물 범주보다 가게물건 범주에서 더 
많았음을 보고한 연구(Kang, Chin, Na, Lee, \& Park, 2000)가 있고, 그와는 반대로 여성이 남성보다 동물 범주에서 더 많은 반응 수를 보였다는 연구도 있으며(Weiss, Kemmler, Deisenhammer, Fleischhacker, \& Delazer, 2003), 의미 유창성에 있어 성차를 발견하지 못한 연구들도 있었다(Choi, 2012a; Kim, Kim, \& Kim, 2011; Lee \& Lee, 2014; Mathuranath et al., 2003; Weiss et al., 2006).

글을 읽고 쓸 줄 아는 능력인 문식성(literacy)과 교육수준이 인 지기능을 평가하는 다양한 신경심리검사에서 피검자의 수행에 영 향을 미치는 것으로 보고되고 있는 바(Ardila, Rosselli, \& Rosas, 1989; Ardila et al., 2010; Kim et al., 2011; Manly et al., 1999; Ostrosky-Solis, Ardila, Rosselli, Lopez-Arango, \& Uriel-Mendoza, 1998), 두 변인이 의미 유창성 수행에 미치는 영향력에 대한 연구는 매우 중요하다. 특히, 평가 대상자가 노인인 경우, 신경심리검사에서 나타 나는 인지기능의 저하가 초기 치매로 인한 것인지 아니면 비문해 또는 저학력으로 인한 결과인지를 명백히 가려내는 것이 어렵기 때 문에(Sa et al., 2011) 연구자들은 노인들의 문식성 여부와 교육수준 이 다양한 인지기능에 미치는 영향력에 대해 많은 연구를 수행하 였다(Hong et al., 2011; Kim, Yoon, Kim, \& Kim, 2014; Kwon et al., 2012; Nitrini et al., 2004). 그러나 앞에서 기술한 바와 같이 외국에 서는 문식성과 교육수준에 따른 의미 유창성의 차이에 대한 연구 가 활발히 진행된 반면 국내에는 기억력이나 다른 인지기능에 비해 서 의미 유창성에 대한 연구는 상대적으로 부족한 실정이다. 한국 노인의 경우, 문식성은 의미 유창성에 어떠한 영향을 미칠까? 문해 자라 하더라도 교육수준에 따라서 의미 유창성에 차이가 있을까? 문식성과 교육수준의 효과가 동물 범주와 가게물건 범주에서 같을 까? 본 연구는 이와 같은 질문들에 대한 해답을 찾을 목적으로 수
행되었다. 정상노인들을 문식성과 교육수준에 따라 7 개 집단으로 세분화한 후 동물 범주와 가게물건 범주 각각에서 의미 유창성의 집단 간 수행 차이를 비교함으로써 문식성과 교육수준에 따른 집 단 간 의미 유창성의 차이 양상을 확인하고 그 결과가 의미범주(동 물과 가게물건)에 따라서 차이가 있는지 살펴 보았다.

\section{연구 방법}

\section{연구 대상}

건강 선별 기준(Christensen, Multhaup, Nordstrom, \& Voss, 1991)에 부합하고 한국형 간이정신상태검사(Korean Mini-Mental State Examination, K-MMSE; Kang, 2006)에서 16\%ile 이상의 수 행을 보인 정상노인 중 주관적 우울감을 평가하는 단축형 노인우 울척도(Short Version of the Geriatric Depression Scale, SGDS; Cho et al., 1999)에서 8점 미만의 점수를 받은 306명(남자 151명, 여 자 155 명)이 참여하였다. 선정된 연구 대상자들의 평균 나이는 72.8 세( $\mathrm{SD}=7.8$, 범위: 60-89세)였다.

연구 대상자들 중 30 명은 K-MMSE의 읽기와 쓰기 문항 중 한 문 항이라도 정상범주에 속하지 않은 사람들로 글을 읽지 못하거나 쓰지 못하는 비문해자(비문해 집단)였고, 나머지 276명은 K-MMSE 의 문항으로 평가된 읽기와 쓰기능력이 모두 정상범주에 속한 문 해자들이었다. 문해자들은 교육수준에 따라서 6개 집단, 즉 “무학 이지만 글을 읽고 쓸 수 있는 집단(무학/문해 집단, 40명)," “초등학 교 저학년(1-3년)까지만 다닌 집단(저-초등 집단, 24명)," “초등학교 고학년(4-6년)까지 다니거나 졸업한 집단(고-초등 집단, 55명)," “중 학교 중퇴나 졸업 집단(중학교 집단, 52명)," “고등학교 중퇴나 졸업

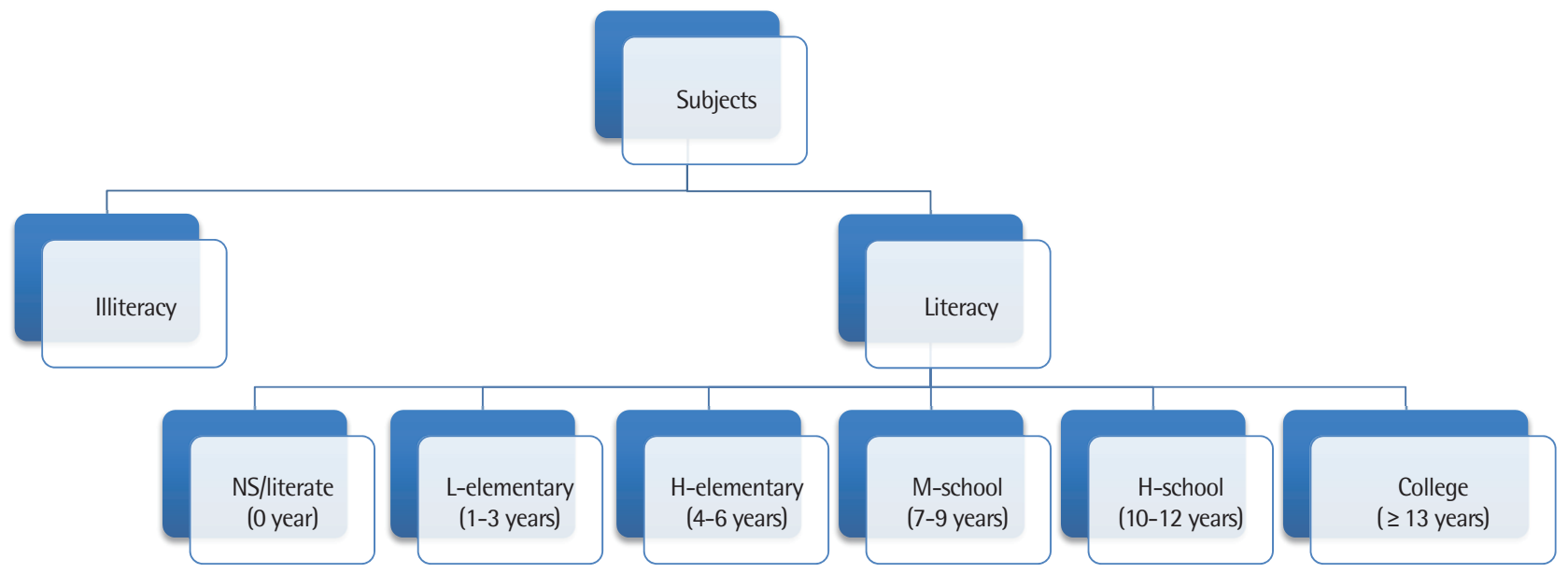

Figure 1. Construction of subject groups. NS/literate = no schooling but literate ( 0 year); L-elementary=lower grade of elementary school (1-3 years); $\mathrm{H}$-elementary = higher grade of elementary school (4-6 years); M-school = middle school (7-9 years); H-school=high school (10-12 years); College ( $\geq 13$ years). 
집단(고등학교 집단, 51명)" 및 “대학교 중퇴 이상 집단(대학 집단, 54명)”으로 분류하였다(Figure 1).

\section{검사 도구 및 절차}

정상노인 대상자를 선별하기 위하여 인지장애와 관련된 다양한 질환들(예: 뇌졸중, 당뇨, 고혈압, 외상성 뇌손상, 간질 등)의 병력에 대해서 확인하는 Christensen 등(1991)의 건강 선별 설문지를 실시 하였고 전반적인 인지기능 수준을 평가하는 K-MMSE와 주관적 우울감을 평가하는 SGDS를 실시하였다.

선정된 모든 연구 대상자들에게 현재 국내 임상장면에서 가장 많이 사용되고 있는 동물 범주와 가게물건 범주에 대한 의미 유창 성검사를 개인검사로 실시한 다음 의미 유창성검사와의 비교를 위 해서 문해자들에게는 ᄀ, 0 , 세 대한음소유창성검사도 함께 개 인검사로 실시하였다(Kang, Jang, \& Na, 2012). 의미 유창성검사와 음소 유창성검사는 COWAT (Lucas et al., 1998)의 실시방법을 적 용하여 각 시행 당 1 분간 반응하도록 하였고 모든 반응을 순서대로 반응기록지에 기록하였다. 반복반응과 해당 범주에 속하지 않은 반응은 점수에서 제외하였고, 고유명사나 주어진 음소로 시작하지 않은 오반응도 점수에서 제외하였다. 상위 개념의 단어(예: 새)와 하 위 개념의 단어(예: 비둘기, 참새, 까마귀)를 함께 반응한 경우에는 상위 개념의 단어를 채점에서 제외시키고 하위 개념의 단어들에만 점수를 주었다. 파생어(예: 우유, 우유병, 우유팩)는 첫 반응에만 점 수를 주었고, 자주 사용되는 외국어, 외래어 및 한글사전(National Institute of Korean Language, 2015)에 수록된 사투리는 정반응으 로 간주하였다.

\section{자료 분석}

인구학적 변인과 SGDS 점수의 집단 간 차이를 확인하기 위하여 일원변량분석(ANOVA)과 $\chi^{2}$ 검증을 실시하였고, 의미 유창성과 음
소 유창성에 영향을 미치는 변인을 확인하기 위하여 다중회귀분석 (multiple regression analysis)을 동시투입(enter)방식으로 실시하였 다. 인구학적 변인 중 집단 간 차이가 발견된 변수들을 공변인(covariates)으로 통제하고 교육수준(7개 집단)을 독립변인, 두 범주의 의미 유창성 점수들을 종속변인으로 한 다변량공분산분석 (MANCOVA)을 실시하였다. 또한 집단 간 차이를 구체적으로 확 인하기 위하여 사후검증으로 Bonferroni 조정 후 단변량 분석(univariate analysis)을 실시하였다. 모든 통계적 분석은 SPSS version 21.0을 사용하여 수행되었다.

\section{연구 결과}

\section{연구 대상의 인구학적 변인과 SGDS}

비문해 집단, 무학/문해 집단, 저-초등 집단, 고-초등 집단, 중학교 집단, 고등학교 집단 및 대학 집단, 전체 7개 집단의 인구학적 변인 들, 즉 나이, 성별, 교육년수의 차이를 확인하기 위하여 일변량분산 분석(ANOVA)과 $\chi^{2}$ 검증을 실시하였다. 그 결과 교육년수 $\left(F_{(6,299)}=\right.$ $2863.34, p<.001)$, 성별 $\left(\chi^{2}=20.05, p<.01\right)$ 및 나이 $\left(F_{(6,299)}=3.85\right.$, $p<.01$ )에 있어서 집단 간 차이가 모두 발견되었다(Table 1). 또한주 관적 우울감을 평가하는 척도인 SGDS의 점수 $\left(F_{(6,299)}=2.96, p<.01\right)$ 에 있어서도 집단 간 유의미한 차이가 발견되었다. 따라서 교육수 준에 따른 집단 간 동물 범주와 가게물건 범주의 수행차이를 확인 하기 위한 모든 통계분석은 나이, 성별 및 SGDS 점수를 통제한 후 실시되었다.

\section{의미 유창성에 영향을 미치는 변인}

의미 유창성에 영향을 미치는 변인을 확인하기 위하여 다중회귀 분석(multiple regression analysis)을 동시입력(enter)방식으로 실시 하였다(Table 2). 그 결과 동물 범주의 경우, 교육년수 $\left(\beta=.41, t_{(301)}=\right.$

Table 1. Subjects' demographical characteristics and SGDS

\begin{tabular}{|c|c|c|c|c|c|c|c|c|c|}
\hline & $\begin{array}{l}\text { Illiterate } \\
\text { (A) }\end{array}$ & $\begin{array}{l}\text { NS/literate } \\
\text { (B) }\end{array}$ & $\begin{array}{l}\text { L-elementary } \\
\text { (C) }\end{array}$ & $\begin{array}{l}\text { H-elementary } \\
\text { (D) }\end{array}$ & $\begin{array}{l}\text { M-school } \\
\text { (E) }\end{array}$ & $\begin{array}{l}\text { H-school } \\
\text { (F) }\end{array}$ & $\begin{array}{l}\text { College } \\
\text { (G) }\end{array}$ & For $\chi^{2}$ & Post-hoc (Bonferroni) \\
\hline No. of subjects & 30 & 40 & 24 & 55 & 52 & 51 & 54 & & \\
\hline Age (yr) & $76.13(6.90)$ & $76.65(8.00)$ & $72.75(6.75)$ & $71.89(7.87)$ & $71.58(7.99)$ & $72.37(7.49)$ & $70.59(7.23)$ & $3.85^{* *}$ & $\begin{array}{c}\mathrm{A}=\mathrm{B}=\mathrm{C}=\mathrm{F}, \mathrm{A}=\mathrm{B}>\mathrm{G}, \mathrm{A}=\mathrm{C}=\mathrm{D}=\mathrm{E}=\mathrm{F}, \\
\mathrm{B}>\mathrm{D}=\mathrm{E}, \mathrm{C}=\mathrm{D}=\mathrm{E}=\mathrm{F}=\mathrm{G}\end{array}$ \\
\hline Sex (male:female) & $7: 23$ & $15: 25$ & $7: 17$ & $31: 24$ & $30: 22$ & $30: 21$ & $31: 23$ & $\chi^{2}=20.05^{* *}$ & 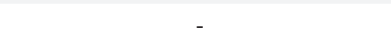 \\
\hline Education (yr) & $0(0)$ & $0(0)$ & $2.42(.78)$ & $5.71(.69)$ & $8.58(.75)$ & $11.71(.64)$ & $15.24(1.08)$ & $2863.34^{* * *}$ & $\mathrm{~A}=\mathrm{B}<\mathrm{C}<\mathrm{D}<\mathrm{E}<\mathrm{F}<\mathrm{G}$ \\
\hline SGDS & $2.70(2.41)$ & $2.98(2.36)$ & $3.25(2.33)$ & $2.42(2.08)$ & $1.96(1.79)$ & $1.89(1.88)$ & $1.68(2.08)$ & $2.96^{* *}$ & $\begin{array}{c}\mathrm{A}=\mathrm{B}=\mathrm{C}=\mathrm{D}=\mathrm{E}, \mathrm{A}=\mathrm{B}=\mathrm{C}>\mathrm{F}=\mathrm{G}, \\
\mathrm{D}=\mathrm{E}=\mathrm{F}=\mathrm{G}\end{array}$ \\
\hline
\end{tabular}

Values are presented as number or mean (SD).

SGDS=Short Version of the Geriatric Depression Scale; NS/literate= no schooling but literate (0 year); L-elementary= lower grade of elementary school (1-3 years); $\mathrm{H}$-elementary= higher grade of elementary school (4-6 years); $\mathrm{M}$-school = middle school (7-9 years); H-school = high school (10-12 years); College ( $\geq 13$ years).

${ }^{* *} p<.01,{ }^{* * *} p<.001$. 
$7.97, p<.001)$, 나이 $\left(\beta=-.21, t_{(301)}=-4.25, p<.001\right)$, 성별 $(\beta=-.11$, $\left.t_{(301)}=-2.15, p<.05\right)$ 및 SGDS 점수 $\left(\beta=-.10, t_{(301)}=-1.99, p<.05\right)$ 순 으로 의미 유창성에 영향을 미치는 것으로 밝혀졌다. 가게물건 범 주의 경우에는 교육년수 $\left(\beta=.52, t_{(301)}=10.86, p<.001\right)$, 성별 $(\beta=.30$, $\left.t_{(301)}=6.62, p<.001\right)$, 나이 $\left(\beta=-.18, t_{(301)}=-4.04, p<.001\right)$ 및 SGDS 점수 $\left(\beta=-.14, t_{(301)}=-3.06, p<.01\right)$ 순으로 의미 유창성에 영향을 미 치는 것으로 확인되었다.

의미 유창성과의 비교를 위해서 문해자 집단에만 부가적으로 실 시된 음소 유창성검사에 대해서도 의미 유창성검사의 경우와 동일 한 분석 방법을 실시하였다(Table 2). 그 결과, 의미 유창성과는 달 리 교육년수 $\left(\beta=.59, t_{(272)}=11.85, p<.001\right)$ 만이 음소 유창성에 영향 을 미치는 것으로 나타났다.

Table 2. Variables that influence the semantic and phonemic fluency

\begin{tabular}{lcccc}
\hline & $\mathrm{B}$ & $\beta$ & $t$ & $\mathrm{R}^{2}$ \\
\hline Animal & & & & .31 \\
Age & -.12 & -.21 & $-4.25^{* * *}$ & \\
Sex & -.92 & -.11 & $-2.15^{*}$ & \\
Education & .34 & .41 & $7.97^{* * *}$ & \\
SGDS & -.19 & -.10 & $-1.99^{*}$ & \\
Supermarket & & & & .41 \\
Age & -.15 & -.18 & $-4.04^{* * *}$ & \\
Sex & 3.84 & .30 & $6.62^{* * *}$ & \\
Education & .62 & .52 & $10.86^{* * *}$ & \\
SGDS & .40 & -.14 & $-3.06^{* * *}$ & \\
Phonemic fluency ( ᄀ. ○.人) & & & & .41 \\
Age & .11 & -.08 & -1.71 & \\
Sex & -.29 & -.01 & -.28 & \\
Education & 1.26 & .59 & $11.85^{* * *}$ & \\
SGDS & -.38 & -.08 & -1.63 & \\
\hline
\end{tabular}

SGDS $=$ Short Version of the Geriatric Depression Scale. ${ }^{*} p<.05,{ }^{* *} p<.01,{ }^{* * *} p<.001$.

\section{문식성의 여부와 교육수준에 따른 의미 유창성의 차이}

다중회귀분석 결과에서 교육년수가 인구학적 변인들 중 의미 유 창성에 가장 큰 영향을 미치는 것으로 밝혀진 바 교육의 영향을 더 자세히 살펴보기 위해서 나이, 성별 및 SGDS 점수를 공변인으로 통제하고 7개 집단에 대한 다변량공분산분석(MANCOVA)을 실 시하였고 유의한 결과를 얻었다 $\left(\lambda=.63, F_{(12,590)}=12.74, p<.001\right.$, partial $\left.\eta^{2}=.21\right)$. 동물 범주와 가게물건 범주에서 모두 집단 간 유의 한 차이가 발견되었으나 동물 범주보다 가게물건 범주에서 교육의 효과가 더 큰 것으로 확인되었다 $\left(F_{(6,296)}=13.26, p<.001\right.$, partial $^{2}=$ $.21 ; F_{(6,296)}=21.96, p<.001$, partial $\left.\eta^{2}=.31\right)$ (Table 3).

범주별 집단 차이를 알아보기 위하여 사후검증으로 Bonferroni 조정 후 단변량 분석(univariate analysis)을 실시한 결과 동물 범주 의 경우, 비문해 집단과 무학/문해 집단 간의 유의한 수행차이가 발 견되었고 $(t=-3.22, p<.05)$, 무학/문해 집단부터 중학교 집단까지는 집단간수행차이가 나타나지 않았다. 무학/문해 집단은 고등학교 및 대학 집단과만 유의한 수행차이를 보였고 $(t=3.92, p<.01 ; t=5.34$, $p<.001)$, 저-초등 집단부터 고등학교 집단까지는 수행차이를 보이 지 않은 반면, 대학 집단은 중학교 학력 이하의 집단들과 유의한 수 행차이를 나타냈고 고등학교 집단과는 수행차이를 나타내지 않았 다 $(t=-1.57, \mathrm{~ns})$.

가게물건 범주의 경우, 비문해 집단부터 저-초등 집단까지는 집단 간 수행차이가 관찰되지 않았다. 고-초등 집단은 비문해 집단보다 유의하게 우수한 수행을 보였으나 $(t=4.68, p<.001)$ 무학/문해 집단 이나 저-초등 집단과는 수행차이를 나타내지 않았고 $(t=2.81, \mathrm{~ns}$; $t=1.10, \mathrm{~ns})$, 중학교와 고등학교 집단과도 수행차이를 나타내지 않았 다 $(t=-1.30, \mathrm{~ns} ; t=-3.02, \mathrm{~ns})$. 중학교 집단은 무학/문해 집단보다 유 의하게 우수한 수행을 보였으나 $(t=3.93, p<.01)$ 두 초등 집단과는 차이를 나타내지 않았다 $(t=2.09, \mathrm{~ns} ; t=1.30, \mathrm{~ns})$. 또한, 대학 집단은 고등학교 집단보다 유의하게 우수한 수행을 보였다 $(t=3.43, p<.05)$.

Table 3. The number of response in semantic and phonemic fluency

\begin{tabular}{|c|c|c|c|c|c|c|c|c|c|c|}
\hline & $\begin{array}{l}\text { Illiterate } \\
\text { (A) }\end{array}$ & $\begin{array}{l}\text { NS/literate } \\
\text { (B) }\end{array}$ & $\begin{array}{l}\text { L-elementary } \\
\text { (C) }\end{array}$ & $\begin{array}{l}\text { H-elementary } \\
\text { (D) }\end{array}$ & $\begin{array}{l}\text { M-school } \\
\text { (E) }\end{array}$ & $\begin{array}{l}\text { H-school } \\
\text { (F) }\end{array}$ & $\begin{array}{l}\text { College } \\
\text { (G) }\end{array}$ & $F$ & partial $\eta^{2}$ & Post-hoc (Bonferroni) \\
\hline Animal & $10.30(3.57)$ & $13.10(3.18)$ & 14.42 (3.91) & $15.31(2.68)$ & $15.83(4.38)$ & $17.14(3.88)$ & $18.43(4.17)$ & $13.26^{* * *}$ & .21 & $\begin{array}{c}\mathrm{A}<\mathrm{B}=\mathrm{C}=\mathrm{D}=\mathrm{E}<\mathrm{G}, \\
\mathrm{C}=\mathrm{D}=\mathrm{E}=\mathrm{F}, \mathrm{B}<\mathrm{F}, \mathrm{F}=\mathrm{G}\end{array}$ \\
\hline Supermarket & $10.90(4.67)$ & $12.55(4.52)$ & $14.96(5.71)$ & $15.71(5.48)$ & $17.04(5.84)$ & $18.75(4.60)$ & $22.33(6.46)$ & $21.96^{* * *}$ & .31 & $\begin{array}{c}\mathrm{A}=\mathrm{B}=\mathrm{C}<\mathrm{F}<\mathrm{G}, \mathrm{A}<\mathrm{D}=\mathrm{E}=\mathrm{F}, \\
\mathrm{B}=\mathrm{C}=\mathrm{D}, \mathrm{B}<\mathrm{E}, \mathrm{C}=\mathrm{D}=\mathrm{E}\end{array}$ \\
\hline $\begin{array}{l}\text { Phonemic fluency } \\
(\neg \cdot 0 \cdot \text { ㅅ) }\end{array}$ & - & $11.75(6.40)$ & $15.21(8.52)$ & $21.02(8.36)$ & $24.90(8.59)$ & $26.90(8.75)$ & $32.63(9.35)$ & $35.57^{* * *}$ & .40 & $\begin{array}{c}\mathrm{B}<\mathrm{D}<\mathrm{F}, \mathrm{B}=\mathrm{C}<\mathrm{E}=\mathrm{F}<\mathrm{G} \\
\mathrm{C}=\mathrm{D}, \mathrm{D}=\mathrm{E}\end{array}$ \\
\hline
\end{tabular}

Values are presented as mean (SD).

NS/literate= no schooling but literate (0 year); L-elementary=lower grade of elementary school (1-3 years); H-elementary=higher grade of elementary school (4-6 years); Mschool = middle school (7-9 years); $H$-school = high school (10-12 years); College ( $\geq 13$ years).

${ }^{* * *} p<.001$. 


\section{교육수준에 따른 음소 유창성의 차이}

다중회귀분석 결과, 교육년수만이 음소 유창성에 영향을 미치는 것으로 밝혀졌으므로 교육수준의 영향을 좀 더 자세히 살펴보기 위해서 집단(6개 문해 집단)을 독립변인으로, 음소 유창성검사의 총 반응수를 종속변인으로 하는 일원변량분산분석(ANOVA)을 실시하였다. 그 결과 집단에 따라서 음소 유창성검사의 수행에 차 이가 있음을 다시 확인하였다 $\left(F_{(5,270)}=35.57, p<.001\right.$, partial $\eta^{2}=$ .40) (Table 3). 사후분석 결과, 무학/문해 집단은 저-초등 집단과는 수행차이를 나타내지 않았으나 $(t=-1.59, \mathrm{~ns})$ 고-초등 집단보다는 유의하게 저조한 수행을 보였다 $(t=-5.28, p<.001)$. 저-초등 집단의 경우고-초등 집단과는 유의한수행차이를 보이지 않았으나 $(t=-2.81$, $n s)$ 중학교 집단보다는 저조한 수행을 나타냈다 $(t=-4.65, p<.001)$. 또한 고-초등 집단은 고등학교 집단보다 저조한 수행을 보였고 $(t=$ $-3.58, p<.01)$, 중학교 집단은 대학 집단보다 저조한 수행을 보인 것 으로 확인되었다 $(t=-3.47, p<.01)$.

\section{논의 및 결론}

본 연구는 한국 노인들을 문식성과 교육수준에 따라서 7개 집단 으로 세분한 후 문식성과 교육수준에 따른 의미 유창성의 수행차 이를 살펴보고, 그러한 수행차이가 의미범주에 따라서도 차이를 보이는지 살펴보기 위해서 수행되었다. 연구 결과, 나이, 성별 및 교 육년수가 모두 의미 유창성에 영향을 미치고, 그 중에서 교육년수 가 동물과 가게물건 범주 모두에서 의미 유창성에 가장 큰 영향을 미치는 변인인 것으로 밝혀졌다. 이는 의미기억(semantic memory) 으로부터 정보를 탐색하고 인출하는 능력에 있어서 교육수준이 매 우 중요한 영향을 미친다는 사실을 시사한다. Sa 등(2011)은 교육 수준이 낮을수록 의미지식의 구조가 덜 체계적으로 조직화되어 있 고 이러한 질적인 차이가 통제연상단어검사와 같은 언어적 개념형 성 과제에서 나타나는 비문해 및 저학력 노인의 저조한 수행과 관련 이 있을 것이라고 주장하였다. 또한 SGDS 점수도 동물과 가게물건 범주 모두에 영향을 미치는 것으로 밝혀졌는데, 이는 젊은 중. 장년 층과 노년층 모두 우울한 집단이 정상 집단보다 의미 유창성검사에 서 더 저조한 수행을 보인 바 우울수준이 의미 유창성에 영향을 미 친다고 보고한 선행연구와 일치하는 결과이다(Lockwood, Alexopoulos, \& van Gorp, 2002).

의미 유창성의 특성과 비교하기 위해서 비문해 집단을 제외한 6 개 문해 집단들의 음소 유창성검사 수행을 분석한 결과, 음소 유창 성에는 인구학적 변인들 중에서 교육년수만이 영향을 미치는 것으 로 밝혀졌고 그 영향력이 두 범주의 의미 유창성보다 더 큰 것으로
관찰되었다 (partial $\eta^{2}=.40$ vs. $\eta^{2}=.21$ and $\left.\eta^{2}=.31\right)$. 이러한 결과들 은 문식성 여부 뿐만 아니라 교육경험이 구어 유창성의 발달에 매 우 중요한 역할을 하고 있음을 시사하며 특히 음소 유창성에 있어 상대적으로 교육의 영향이 더 크다는 사실을 선행연구들에서와 같 이 보여 준다(Choi, 2012b; Selnes et al., 1991; Yeudall et al., 1986).

문식성과 교육수준에 따른 집단 간 의미 유창성의 차이를 다변 량공분산분석을 통해서 살펴본 결과 동물 범주와 가게물건 범주 에서 모두 집단 간 유의한 수행 차이가 발견되었으나 교육수준에 따른 집단 간 차이는 동물 범주보다 가게물건 범주에서 더 큰 것으 로 확인되었다. 집단 간 차이를 더 자세히 분석하기 위해서 각 범주 별로 사후분석을 실시하였다. 분석 결과, 동물 범주에서는 비문해 집단과 무학/문해 집단 간 수행 차이가 관찰된 반면, 가게물건 범주 에서는 비문해 집단과 무학/문해 집단 간의 수행 차이가 관찰되지 않았고 비문해 집단은 저-초등 집단과도 수행차이를 나타내지 않 았다. 뿐만 아니라 동물 범주의 경우, 학교를 다니지는 않았으나 글 을 아는 무학/문해 집단부터 중학교 집단까지는 유의한 수행 차이 가 나타나지 않았고 고등학교 집단이 되어서야 무학/문해 집단과 유의한 수행 차이가 관찰된 반면, 가게물건 범주에서는 고-초등 집 단이 비문해 집단보다, 중학교 집단이 무학/문해 집단보다 우수한 수행을 보였다. 대학 집단은 동물 범주에서는 고등학교 집단과 차 이가 없었으나 가게물건 범주에서는 고등학교 집단보다 우수한 수 행을 보였다.

이러한 결과는 동물 범주의 경우에는 교육수준의 효과뿐만 아 니라 문식성의 여부(문해 vs. 비문해)에 따른 의미 유창성의 차이가 더 크고, 가게물건 범주에서는 문식성의 여부보다는 교육수준에 따른 의미 유창성의 차이가 더 크다는 사실을 시사한다. 동물 범주 의 경우, 학교를 다니지는 않았지만 다른 경로로 한글을 깨우친 사 람은 한글을 전혀 모르는 사람보다 우수한 수행을 보였고, 초등학 교나 중학교를 졸업한 사람들과는 수행 차이를 보이지 않았다. 이 집단은 고등학교 이상 집단하고만 수행차이를 보였다. 이와 같은 결 과는 동물 범주의 경우 교육의 영향도 존재하나, 문식성이 매우 중 요한 요인임을 보여준다.

반면에 가게물건 범주의 경우, 비문해 집단의 수행수준이 학교 교육을 받지는 못했으나 글을 깨우친 무학/문해 집단이나 초등학 교를 저학년만 다닌 저-초등 집단과 차이가 없었다는 사실은 문식 성이 가게물건 범주에서는 동물 범주만큼 중요한 영향을 미치는 변 인이 아님을 시사한다. 사후분석 결과가 보여주듯이 바로 인접한 집단과는 유의한 수행차이가 없으나 교육수준이 증가함에 따라 수 행수준이 계속 증가하고 교육수준이 2-3개 높거나 낮은 집단과 유 의한 수행차이를 보였다는 사실은 가게물건 범주의 의미 유창성이 
교육수준의 영향을 많이 받음을 시사하는 결과이다.

이런 결과는 가게물건 범주보다 동물 범주에서 교육수준의 효과 가 더 크므로 비문해 터키 이민자들의 생성이름대기 능력을 평가 할 때 가게물건 범주를 사용할 것을 주장한 Nielsen과 Waldemar (2016)의 결과와는 상반되는 듯이 보인다. 그러나 Nielsen과 Walde$\operatorname{mar}$ (2016)가 본 연구와는 다른 결과를 발견한 것은 이들이 연구대 상으로 사용한 집단이 비문해 집단과 문해 집단(평균 교육년수 5 년)으로 제한되어 있었기 때문으로 추측된다. 이런 추측을 실제로 확인하기 위해서 저자들은 본 연구에 참여한 연구 대상자들 중 중 학교 집단까지만 선별하여 평균 교육년수를 Nielsen과 Waldemar (2016)의 연구와 비슷하게 4.9년으로 맞춘 후 비문해 집단과 문해 집단으로 나누어 두 집단의 의미 유창성을 비교하였다. 분석 결과 는 Nielsen과 Waldemar (2016)의 결과와 동일하게 동물 범주 $(t=$ -5.86, $p<.001$, partial $\left.\eta^{2}=.15\right)$ 가 가게물건 범주 $(t=-3.52, p<.01$, partial $\left.\eta^{2}=.06\right)$ 보다 교육수준의 효과가 더 큰 것으로 나타났다. 이 결과는 본 연구자들이 선행연구들의 비일관적인 결과의 원인으로 예상한 바와 같이 문해 집단을 어떻게 구성하는가에 따라서 매우 다른 결과가 초래될 수 있음을 실제적으로 보여준다. 본 연구에서 처럼 문해 집단을 초등학교부터 대학교육에 이르기까지 광범위하 게 포함시키고 교육수준에 따라서 집단을 세분하는 것이 교육수준 의 영향을 정확히 볼수 있는 보다 타당한 방법일 것이다.

본 연구와 대부분의 선행연구들은 비문해자/무학, 문해자/저학 력 등으로 문식성(literacy)과 교육수준을 조합하여 집단을 구성하 였으나 최근에 국내에서 수행된 한 연구에서는 문식성 수준을 문 식성 검사(Kim et al., 2014)를 사용하여 4단계(pure-illiterate, semiilliterate, literate, \& high-literate)로 구분하고 의미 유창성에 미치 는 문식성의 영향을 살펴보았다(Kim, Lee, \& Yoon, 2015). 연구 결 과에 따르면, 동물 범주에서는 문식성 수준에 따른 의미 유창성의 수행 차이가 발견되지 않았으나, 가게물건 범주에서는 고수준 문해 집단(high-level literate group)이 순수-비문해 집단(pure-illiterate group)이나 반-비문해 집단(semi-illiterate group)보다 유의하게 우 수한 수행을 보였고, 문해 집단(literate group)과는 차이가 관찰되 지 않았다. 이 결과를 본 연구의 결과와 직접 비교하는 것은 불가능 하지만 우선, 동물 범주보다 가게물건 범주에서 문식성의 효과가 더 크게 나타난 결과는 본 연구의 결과와 일치하는 결과라고 말할 수 있을 것이다. 그러나 본 연구 결과와는 달리 동물 범주의 경우 4 집단 간 차이가 나타나지 않은 이유를 알아보기 위해서 본 연구의 대상자들을 Kim, Lee 등(2015)이 사용한 것과 같은 기준으로 다시 분류하였다. 그 결과 본 연구의 비문해 집단은 모두 순수-비문해 집 단으로 분류되었고, 무학/문해 집단과 저-초등 집단은 대부분 문해
집단으로 분류되었으나 소수는 반-비문해 집단으로 분류되었으며, 고-초등 집단의 경우는 문해 집단과 고수준 문해 집단이 비슷한 비 율로 섞여 있었다. 그리고, 중학교 집단 이상은 모두 고수준 문해 집 단이었다. 이런 결과는 문식성에 따른 분류가 우리나라의 교육수 준에 따른 분류와는 일치하지 않는다는 것을 시사한다. 문식성에 기반한 분류와 교육년수에 입각한 전통적인 분류방식이 의미 유창 성에 관한 연구에 사용될 때 어떤 결과의 차이를 가져오는지는 추 후 연구에서 밝혀져야 할 것이다.

본 연구는 비문해자와 비교하기 위해서 제한된 범위의 낮은 교 육수준만을 포함시킨 선행연구들의 문제점을 밝히고, 연구 대상으 로 비문해자에서부터 대학교육을 받은 사람에 이르기까지 집단을 세분화하여 전체 교육범위를 포함함으로써 선행연구와 다른 결과 를 발견하였다는데 의의가 있다. 또한, 의미 유창성검사의 동물 범 주와 가게물건 범주가 각각 문식성과 교육수준에 따라 서로 다른 양상을 보인다는 점을 확인하였다. 일상생활에서 접할 수 있는 동 물의 종류는 제한되어 있고 우리는 책이나 다른 매체를 통해서 간 접적으로 다양한 동물에 대한 지식을 얻게 된다. 그러나 가게물건 에 비하면 책이나 다른 매체를 통해서 간접적으로 알게 되는 동물 의 종류와 수는 다소 제한되어 있다. 따라서 문식성(문해)의 여부 가 동물 범주의 의미 유창성에 중요한 영향을 미치지만 일단 글을 알게 되더라도 교육수준에 따른 효과는 상대적으로 그리 크지 않 을 것으로 보인다. 반면에 가게물건 범주의 경우에는 문식성(문해) 의 여부에 관계없이 비문해자도 일상적인 구매활동을 통해서 무 학/문해자와 차이가 없는 기본적인 의미지식 구조를 가지게 되지 만 교육수준이 높을수록 대체로 사회경제적 지위도 높고 구매활 동의 범위와 내용이 다양화되므로 정보가 많아져서 가게물건 범주 에 대한 의미지식 구조가 더 체계화되고 조직화될 것으로 생각된 다. Sa 등(2011)은 가게물건 범주에서 문해/저교육 집단보다 문해/ 고교육 집단이 반응의 세부범주 전환수가 유의미하게 많은 것으로 보고하였다. 이 결과는 본 저자들이 추론하였듯이 문해/고교육 집 단이 문해/저교육 집단보다 가게물건 범주의 의미지식 구조가 더 복잡하고, 더 다양한 하위범주를 지니고 있음을 시사하며, 가게물 건 범주에 미치는 교육의 효과를 증명한다. 따라서 임상현장에서 생성이름대기능력을 평가하고 비교할 때 피검자의 특성(비문해 vs. 문해; 저학력 vs. 고학력)을 고려하여 적절한 범주를 선택하고, 검 사 결과를 해석할 때에도 유의해야 할 것으로 생각된다. 본 연구의 결과에 따르면, 비문해자를 평가해야 한다면 문해/비문해의 차이 를 보이지 않는 가게물건 범주를 사용하고, 피검자가 문해자, 특히 저학력 문해자라면 교육의 영향을 적게 받는 동물 범주를 사용하 는 것이 더 적절하다고 말할 수 있다. 
끝으로, 본 연구는 임상장면에서 가장 흔히 사용되고 있는 동물 과 가게물건 범주만을 대상으로 수행되었다. 과일, 채소, 음식, 옷, 가구 등 다른 범주에서는 의미 유창성에 미치는 문식성과 교육의 효과가 어떠한지와 이런 다양한 범주 중에서 비문해자와 저학력자 에게 동물이나 가게물건 범주보다 더 적절한 범주가 있는지는 추후 연구에서 검증되어야 할 것이다. 또한, 본 연구에서는 학력 집단을 구분할 때 보통은 1학년부터 6학년까지 한 집단으로 분류하는 초 등학교 집단을 1 학년에서 3 학년까지의 “저-초등 집단”과 4학년에 서 6학년까지의 “고-초등 집단”으로 세분하였다. 의미 유창성의 수 행향상을 살펴보면(Table 3) 저-초등 집단은 무학/문해 집단과 유 사한 수준의 수행을 보이고 고-초등 집단은 중학생 집단과 유사한 수준의 수행을 보인 것을 알 수 있다. 이와같은 결과는 초등학교 학 력을 한 집단이 아니라 이렇게 두 집단(수준)으로 세분하는 것이 타당하다는 사실을 보여준다. 문식성과 교육수준이 언어 검사를 비롯한 다양한 신경심리검사의 수행에 영향을 미치는 것으로 보고 되어 왔고(Ardila et al., 2010; Kim et al., 2011) 신경심리검사들은 나이와 학력 또는 성별에 따른 규준을 제시하고 있다. 본 연구는 새 로운 검사 도구의 규준을 개발할 때 교육수준의 차이가 수행에 미 치는 영향에 대한 경험적인 연구를 통해서 교육수준을 세분할 필 요가 있음을 시사한다.

\section{REFERENCES}

Abrahams, S., Leigh, P. N., Harvey, A., Vythelingum, G. N., Grise, D., \& Goldstein, L. H. (2000). Verbal fluency and executive dysfunction in amyotrophic lateral sclerosis (ALS). Neuropsychologia, 38, 734-747.

Acevedo, A., Loewenstein, D. A., Barker, W. W., Harwood, D. G., Luis, C., Bravo, M., ... \& Duara, R. (2000). Category fluency test: normative data for English- and Spanish-speaking elderly. Journal of the International Neuropsychological Society, 6, 760-769.

Ardila, A., Bertolucci, P. H., Braga, L. W., Castro-Caldas, A., Judd, T., Kosmidis, M. H., ... \& Rosselli, M. (2010). Illiteracy: the neuropsychology of cognition without reading. Archives of Clinical Neuropsychology, 25, 689-712.

Ardila, A., Ostrosky-Solis, F., Rosselli, M., \& Gómez, C. (2000). Age-related cognitive decline during normal aging: the complex effect of education. Archives of Clinical Neuropsychology, 15, 495-513.

Ardila, A., Rosselli, M., \& Rosas, P. (1989). Neuropsychological assessment in illiterates: visuospatial and memory abilities. Brain and Cognition, 11, 147166.

Baldo, J. V., Schwartz, S., Wilkins, D., \& Dronkers, N. F. (2006). Role of fron- tal versus temporal cortex in verbal fluency as revealed by voxel-based lesion symptom mapping. Journal of the International Neuropsychological Society, 12, 896-900.

Birn, R. M., Kenworthy, L., Case, L., Caravella, R., Jones, T. B., Bandettini, P. A., \& Martin, A. (2010). Neural systems supporting lexical search guided by letter and semantic category cues: a self-paced overt response fMRI study of verbal fluency. Neuroimage, 49, 1099-1107.

Bolla, K. I., Lindgren, K. N., Bonaccorsy, C., \& Bleecker, M. L. (1990). Predictors of verbal fluency (FAS) in the healthy elderly. Journal of Clinical Psychology, 46, 623-628.

Brucki, S. M. D., \& Rocha, M. S. G. (2004). Category fluency test: effects of age, gender and education on total scores, clustering and switching in Brazilian Portuguese-speaking subjects. Brazilian Journal of Medical and Biological Research, 37, 1771-1777.

Capitani, E., Laiacona, M., \& Basso, A. (1998). Phonetically cued word-fluency, gender differences and aging: a reappraisal. Cortex, 34, 779-783.

Cho, M. J., Bae, J. N., Suh, G. H., Hahm, B. J., Kim, J. K., Lee, D. W., \& Kang, M. H. (1999). Validation of geriatric depression scale, Korean version (GDS) in the assessment of DSM-III-R major depression. Journal of Korean Neuropsychiatric Association, 38, 48-63.

Choi, H. (2012a). Performances of verbal fluency task in normal elderly: effects of gender and educational level by categories. Journal of Speech and Hearing Disorder, 21, 37-52.

Choi, H. (2012b). Expressive language function in the normal elderly: effects of gender and educational level. Special Education Research, 11, 131-146.

Christensen, K. J., Multhaup, K. S., Nordstrom, S., \& Voss, K. (1991). A cognitive battery for dementia: development and measurement characteristics. Psychological Assessment, 3, 168-174.

Da Silva, C. G., Petersson, K. M., Faisca, L., Ingvar, M., \& Reis, A. (2004). The effects of literacy and education on the quantitative and qualitative aspects of semantic verbal fluency. Journal of Clinical and Experimental Neuropsychology, 26, 266-277.

Fahlander, K., Wahlin, Å., Almkvist, O., \& Bäckman, L. (2002). Cognitive functioning in Alzheimer's disease and vascular dementia: further evidence for similar patterns of deficits. Journal of Clinical and Experimental Neuropsychology, 24, 734-744.

Geiser, D. S., \& Vanderploeg, R. D. (1993). Age and education effect on verbal fluency in the elderly. Paper presented at the Meeting of the American Psychological Association, Evanston, IL.

Hart, R. P., \& Best, A. M. (2014). Neuropsychological profile and performance 
variability in vascular cognitive impairment. International Journal of Clinical Medicine, 5, 1047-1058.

Henry, J. D., MacLeod, M. S., Phillips, L. H., \& Crawford, J. R. (2004). A meta-analytic review of prospective memory and aging. Psychology and Aging, 19, 27-39.

Hock, C., Villringer, K., Müller-Spahn, F., Wenzel, R., Heekeren, H., SchuhHofer, S., ... \& Villringer, A. (1997). Decrease in parietal cerebral hemoglobin oxygenation during performance of a verbal fluency task in patients with Alzheimer's disease monitored by means of near-infrared spectroscopy (NIRS) - correlation with simultaneous rCBF-PET measurements. Brain Research, 755, 293-303.

Hong, Y. J., Yoon, B., Shim, Y. S., Cho, A. H., Lee, E. S., Kim, Y. I., \& Yang, D. W. (2011). Effect of literacy and education on the visuoconstructional ability of non-demented elderly individuals. Journal of the International Neuropsychological Society, 17, 934-939.

Jones, S., Laukka, E. J., \& Bäckman, L. (2006). Differential verbal fluency deficits in the preclinical stages of Alzheimer's disease and vascular dementia. Cortex, 42, 347-355.

Jung, K. H., Oh, Y. H., Kang, E. N., Kim, J. H., Seon, W. D., Oh, M. A., ... \& Lee, G. R. (2014). An investigation of the elderly in 2014. Seoul: Korea Institute for Health and Social Affairs.

Kang, Y. (2006). A normative study of the Korean-Mini Mental State Examination (K-MMSE) in the elderly. Korean Journal of Psychology: General, $25,1-12$.

Kang, Y. W., Chin, J. H., Na, D. L., Lee, J. H., \& Park, J. S. (2000). A normative study of the Korean version of Controlled Oral Word Association Test (COWAT) in the elderly. Korean Journal of Clinical Psychology, 19, 385-392.

Kang, Y., Jang, S. M., \& Na, D. L (2012). Seoul Neuropsychological Screening Battery (2nd ed.). Seoul: Human Brain Research and Consulting.

Kim, H. K., Kim, S. Y., \& Kim, T. Y. (2011). Effects of age, education and gender on multiple cognitive measures of Korean older adults. Korean Journal of Clinical Psychology, 30, 681-701.

Kim, H., Kang, Y., Yu, K. H., \& Lee, B. C. (2015). A comparison of the deterioration characteristics in verbal fluency between amnestic mild cognitive impairment and vascular mild cognitive impairment. Communication Sciences and Disorders, 20, 587-595.

Kim, J. W., Lee, S. K., \& Yoon, J. H. (2015). The distinctive effect of providing syllables in letter fluency testing: literate vs. illiterate elderly persons. Speech Communication, 70, 42-48.

Kim, J., Yoon, J. H., Kim, S. R., \& Kim, H. (2014). Effect of literacy level on cognitive and language tests in Korean illiterate older adults. Geriatrics and Gerontology International, 14, 911-917.

Kosmidis, M. H., Tsapkini, K., Folia, V., Vlahou, C. H., \& Kiosseoglou, G. (2004). Semantic and phonological processing in illiteracy. Journal of the International Neuropsychological Society, 10, 818-827.

Kwon, O. D., Cho, S. S., Seo, S. W., \& Na, D. L. (2012). Effect of illiteracy on neuropsychological tests and glucose metabolism of brain in later life. Journal of Neuroimaging, 22, 292-298.

Kwon, O. D., Yoon, U., \& Na, D. L. (2015). Effect of illiteracy on cognition and cerebral morphology in later life. Dementia and Neurocognitive Disorders, $14,149-157$.

Lee, J. Y., \& Lee, O. B. (2014). Verbal fluency and word naming speed in healthy adults. Journal of Speech and Hearing Disorder, 23, 15-22.

Lockwood, K. A., Alexopoulos, G. S., \& van Gorp, W. G. (2002). Executive dysfunction in geriatric depression. American Journal of Psychiatry, 159, 1119-1126.

Loonstra, A. S., Tarlow, A. R., \& Sellers, A. H. (2001). COWAT metanorms across age, education, and gender. Applied Neuropsychology, 8, 161-166.

Lucas, J. A., Ivnik, R. J., Smith, G. E., Bohac, D. L., Tangalos, E. G., Graff-Radford, N. R., \& Petersen, R. C. (1998). Mayo's older Americans normative studies: category fluency norms. Journal of Clinical and Experimental Neuropsychology, 20, 194-200.

Manly, J. J., Jacobs, D. M., Sano, M., Bell, K., Merchant, C. A., Small, S. A., \& Stern, Y. (1999). Effect of literacy on neuropsychological test performance in nondemented, education-matched elders. Journal of the International Neuropsychological Society, 5, 191-202.

Mathuranath, P. S., George, A., Cherian, P. J., Alexander, A. L., Sarma, S. G., \& Sarma, P. S. (2003). Effects of age, education and gender on verbal fluency. Journal of Clinical and Experimental Neuropsychology, 25, 1057-1064.

Mo, K. O., Sung, J. E., \& Jeong, J. H. (2015). The effects of semantic feature analysis treatment on naming performance in Korean individuals with early dementia of the Alzheimer's type: using a familiarity of nouns scale. Communication Sciences and Disorders, 20, 34-47.

National Institute of Korean Language. (2015). Standard Korean language dictionary. Retrieved from http://stdweb2.korean.go.kr.html.

Nielsen, T. R., \& Waldemar, G. (2016). Effects of literacy on semantic verbal fluency in an immigrant population. Aging, Neuropsychology, and Cognition, 23, 578-590.

Nitrini, R., Caramelli, P., Herrera, E., Porto, C. S., Charchat-Fichman, H., Carthery, M. T., ... \& Lima, E. P. (2004). Performance of illiterate and literate non- 
demented elderly subjects in two tests of long-term memory. Journal of the International Neuropsychological Society, 10, 634-638.

Ostrosky-Solis, F., Ardila, A., Rosselli, M., Lopez-Arango, G., \& Uriel-Mendoza, V. (1998). Neuropsychological test performance in illiterate subjects. Archives of Clinical Neuropsychology, 13, 645-660.

Pakhomov, S. V., \& Hemmy, L. S. (2014). A computational linguistic measure of clustering behavior on semantic verbal fluency task predicts risk of future dementia in the Nun study. Cortex, 55, 97-106.

Park, J., Kang, Y., Chang, E. J., Oh, E., Yu, K. H., \& Lee, B. C. (2006). Clustering and switching on verbal fluency in vascular dementia and dementia of the Alzheimer's type. Korean Journal of Communication Disorders, 11, 99112.

Phillips, L. H. (1999). Age and individual differences in letter fluency. Developmental Neuropsychology, 15, 249-267.

Rodriguez-Aranda, C., \& Martinussen, M. (2006). Age-related differences in performance of phonemic verbal fluency measured by Controlled Oral Word Association Task (COWAT): a meta-analytic study. Developmental Neuropsychology, 30, 697-717.

Sa, S. Y., Chey, J. Y., \& Suk, J. S. (2011). Semantic structure of the elderly Koreans as assessed by category fluency test: effects of literacy and education. Korean Journal of Psychology: General, 30, 227-242.

Sauzéon, H., Lestage, P., Raboutet, C., N'Kaoua, B., \& Claverie, B. (2004). Verbal fluency output in children aged 7-16 as a function of the production criterion: qualitative analysis of clustering, switching processes, and semantic network exploitation. Brain and Language, 89, 192-202.
Selnes, O. A., Jacobson, L., Machado, A. M., Becker, J. T., Wesch, J., Miller, E. N., ... \& McArthur, J. C. (1991). Normative data for a brief neuropsychological screening battery. Perceptual and Motor Skills, 73, 539-550.

Troyer, A. K., Moscovitch, M., Winocur, G., Leach, L., \& Freedman, M. (1998). Clustering and switching on verbal fluency tests in Alzheimer's and Parkinson's disease. Journal of the International Neuropsychological Society, 4, $137-143$.

Van Der Elst, W., Van Boxtel, M. P., Van Breukelen, G. J., \& Jolles, J. (2006). Normative data for the Animal, Profession and Letter M Naming verbal fluency tests for Dutch speaking participants and the effects of age, education, and sex. Journal of the International Neuropsychological Society, 12, 80-89.

Weiss, E. M., Kemmler, G., Deisenhammer, E. A., Fleischhacker, W. W., \& Delazer, M. (2003). Sex differences in cognitive functions. Personality and Individual Differences, 35, 863-875.

Weiss, E. M., Ragland, J. D., Brensinger, C. M., Bilker, W. B., Deisenhammer, E. A., \& Delazer, M. (2006). Sex differences in clustering and switching in verbal fluency tasks. Journal of the International Neuropsychological Society, 12, 502-509.

Yeudall, L. T., Fromm, D., Reddon, J. R., \& Stefanyk, W. O. (1986). Normative data stratified by age and sex for 12 neuropsychological tests. Journal of Clinical Psychology, 42, 918-946.

Youn, J. H., Siksou, M., Mackin, R. S., Choi, J. S., Chey, J., \& Lee, J. Y. (2011). Differentiating illiteracy from Alzheimer's disease by using neuropsychological assessments. International Psychogeriatrics, 23, 1560-1568. 


\section{국문초록}

\section{문식성과 교육수준이 한국 노인들의 의미 유창성에 미치는 효과} 이진경' · 강연욱',2

1한림대학교 심리학과, ${ }^{2}$ 한림대학교 성심병원 신경과

배경 및 목적: 본 연구는 한국 노인들을 대상으로 문식성(literacy)과 교육수준이 의미 유창성에 미치는 효과를 확인하고 그 결과가 의 미범주(동물, 가게물건)에 따라서 차이가 있는지 밝히고자 수행되었다. 방법: 306 명의 정상노인(평균 나이 $72.8 \pm 7.8$ 세; 남자 151 명, 여 자 155 명)이 연구에 참여하였고, 문식성과 교육수준에 따라서 7 개 집단(비문해 집단, 무학/문해 집단, 저-초등 집단, 고-초등 집단, 중학 교 집단, 고등학교 집단, 대학 집단)으로 분류되었다. 모든 연구 대상자들에게 의미 유창성검사(동물, 가게물건)를 실시하였다. 결과: 동 물 범주에서는 비문해 집단과 무학/문해 집단 간 의미 유창성의 차이가 관찰되었으나, 가게물건 범주에서는 비문해 집단이 무학/문해 집단이나 저-초등 집단과 의미 유창성의 차이를 보이지 않았다. 또한 동물 범주에서는 무학/문해 집단부터 중학교 집단까지 유의한 수 행차이가 관찰되지 않았고, 고등학교 집단과 대학 집단 간에도 수행차이가 발견되지 않았으나, 가게물건 범주에서는 고-초등 집단이 비 문해 집단보다, 중학교 집단이 무학/문해 집단보다, 그리고 대학 집단이 고등학교 집단보다 우수한 수행을 보였다. 논의 및 결론: 본 연 구의 결과는 동물 범주의 경우에는 교육수준보다 문식성이 의미 유창성에 더 큰 영향을 미치고, 가게물건 범주의 경우는 문식성보다 교육수준이 더 큰 영향을 미친다는 사실을 시사한다.

핵심어: 문식성, 교육수준, 의미 유창성, 동물 범주, 가게물건 범주

본 연구는 2016년도 한림대학교 교비 연구비(HRF-201609-002)와 한국연구재단(NRF-2014S1A5A2A03065709)의 연구비 지원을 받아수행된 연구임.

\section{참고문헌}

강연욱(2006). K-MMSE (Korean-Mini Mental State Examination)의 노인 규준 연구. 한국심리학회지: 일반, 25, 1-12.

강연욱, 장승민, 나덕렬(2012). 서울신경심리검사 2판. 서울: 휴브알엔씨.

강연욱, 진주희, 나덕렬, 이정희, 박재설(2000). 통제 단어 연상 검사 (Controlled Oral Word Association Test)의 노인 규준 연구. 한국심리학회지: 임 상, 19, 385-392.

김해윤, 강연욱, 유경호, 이병철(2015). 기억성 경도인지장애와 혈관성 경도인지장애의 구어 유창성 저하 양상 비교. 언어청각장애연구, 20, 587-595. 김홍근, 김용숙, 김태유(2011). 한국 노인의 연령, 교육수준, 성별이 인지기능 측정치들에 미치는 효과. 한국심리학회지: 임상, 30, 681-701.

모경옥, 성지은, 정지향(2015). 명사 친숙도를 활용한 의미자질중재가 초기 알츠하이머성 치매노인의 이름대기 능력에 미치는 효과. 언어청각장애연 구, 20,34-47.

박재설, 강연욱, 장은주, 오은아, 유경호, 이병철(2006). 혈관성 치매와 알츠하이머형 치매의 단어 유창성 비교: 군집화와 전환. 언어청각장애연구, 11 , 99-112.

사수연, 최진영, 석정서(2011). 범주유창성 과제로 평가한 한국 노인들의 의미지식 구조. 한국심리학회지: 일반, 30, 227-242.

이지윤, 이옥분(2014). 정상성인의 구두유창성과 단어 이름대기 속도의 특성. 언어치료연구, 23, 15-22.

정경희, 오영희, 강은나, 김재호, 선우덕, 오미애, 이윤경, 황남희, 김경래, 오신휘, 박보미, 신현구, 이금룡(2014). 2014년도 노인실태조사. 서울: 한국보건 사회연구원.

조맹제, 배재남, 서국희, 함봉진, 김장규, 이동우, 강민희(1999). DSM-III-R 주요우울증에 대한 한국어판 Geriatric Depression Scale (GDS)의 진단적 타당성 연구. 신경정신의학, 38, 48-63.

최현주(2012a). 고령자의 구어유창성 과제 수행력. 언어치료연구, 21, 37-52.

최현주(2012b). 성별과 교육정도에 따른 고령자의 언어표현 능력의 차이. 특수교육, 11, 131-146. 